\title{
On Human Capital Investment of Poor Population -- Based on the Perspective of Targeted Poverty Alleviation
}

\author{
MAO Yaping \\ Institute of Marxism, Kunming Metallurgy College, Kunming, Yunnan Province, China
}

email: 838313033@qq.com

\begin{abstract}
Keywords: Accurate poverty alleviation, Human capital investment, Intergenerational transmission of poverty.
\end{abstract}

\begin{abstract}
The ultimate realization of the goal of poverty alleviation should not only solve the current poverty phenomenon, but also block the intergenerational transmission of poverty. From the angle of human capital investment of poor people, this paper analyzes the feasibility of educational investment, skill and technology training, labor transfer and improving the health condition of the poor people to solve the problem of poverty, and points out that the development of precision poverty alleviation work needs to increase the investment of the human capital of the poor people and avoid shortsightedness of the poverty alleviation.
\end{abstract}

\section{论贫困人口人力资本投资——基于精准扶贫视角 \\ 毛娅萍 \\ 昆明冶金高等专科学校, 昆明, 云南省, 中国 \\ email:838313033@qq.com}

\section{关键词：精准扶贫 人力资本投资 贫困代际传递}

中文摘要. 精准扶贫目标的最终实现, 不但要解决当下的贫困现象, 更要阻断贫困的代际传 递。本文从贫困人口人力资本投资的角度, 剖析了贫困人口的教育投资、技能技术培训、劳 动力转移及提高贫困人口健康状况对解决贫困问题的可行性, 从而指出精准扶贫工作的开展, 需要加大贫困人口人力资本投资, 避免扶贫行为的短视性。

\section{1. 引言}

当前，我国的扶贫工作已经取得了世界瞩目的成就，正在走向 “最后一公里” 的里程碑。 但这 “最后一公里”，同时也是当下扶贫工作 “最难啃的硬骨头”。精准扶贫除了需要有决 心、外界干预和资金投入外, 还需要对这些资源进行最优化配置, 才能物尽其用。尤其是在 “授人予鱼”与 “授人予渔” 的路径选择上, 需要精准扶贫政策的策略既要解决当下的贫困 现实, 更要杜绝贫困现象的再发生。虽然前人对于贫困问题的解决已经提出了诸多可行的方 案, 但这些合理的措施都有自身适用的维度。加大投资、简化机构、瞄准产业等措施固然可 以加大反贫困的力度, 但是在彻底扫除贫困这一目标上, 这些举措的实施某种意义上有短视 的不足。 


\section{2. 贫困人口人力资本投资是避免贫困代际传递的靶向}

贫困人群所面对的普遍受教育水平低下, 如果不注重人力资本投资, 乡村振兴战略及科 技农业将失去人力资源支撑点, 陷入精准扶贫治标不治本的四塩尬境地。只有把贫困人口的人 力资源开发纳入精准扶贫的考量范围, 才能避免贫困的代际传递, 进而提高反贫困的效率。 人力资本的投资实质上是将货币资本和财富收益内化为自身固有知识和能力形态, 使人力与 其他实物一样具有使用价值和价值。反贫困强调贫困主体的参与能力, 就是要使贫困群体能 够有效地把握和利用提供给他们的发展机会, 就要重视通过人力资本投资。人力资本的投资 主要包括四个方面: 教育、技术培训、劳动力转移和个人健康状况。

\section{3. 贫困人口人力资本投资的具体措施}

\section{1 教育是贫困人口人力资本投资的首要内容}

教育与反贫困之间存在着密切相关性。经济不发达是贫困的原因, 而贫困却高发于低教 育水平人群中。贫困地区制约发展的最薄弱环节是教育和技术。地区之间的差异, 除了收入 水平之外, 最根本的差距就是观念、科学教育。教育的实质是传授价值准则, 但是价值准则 也只有变成或者称之为 “内化” 成自己的一部分才能帮助我们选择生活的道路。也就是说, 这些准则不是生硬的公式或教条, 而应该是思考和感受的工具, 是观察世界、解释世界和体 验世界的工具。

2010年来, 随着国家对贫困地区教育重视程度的不断增强, 农村小学的校舍、师资和教 师待遇等情况有了明显改善, 但始终困扰基础教育的问题是高辍学率。农村与城市的基础教 育差别在于, 以当前的农业性质决定, 绝大多数农村学生将会在农村经历一生, 面对的是以 农业为中心的劳动模式。而目前国家整齐划一的应试教育体制对于提高农业劳动生产率作用 甚微, 从当下实际出发, 在村民还不具备充裕的资金和富余劳动力的前提下, 追求高层次受 教育水平同样是奢谈。为此, 可以在基础教育阶段就明确城乡差别和知识接受差别, 赋予学 生是继续接受教育还是多学习劳动技能和农业知识方面以自主选择权。对于因各种原因无法 继续升学的学生, 可以考虑在小学和初中高年级时期, 对其进行技能培训, 使其掌握农业适 用技术, 即使由于各种原因无法再接受初中教育, 也可以掌握基本生产技能。随着基础教育 投资力度不断加大, 可以在家庭无需为学龄儿童承担教育费用 (学费、资料费、生活费) 的 前提下, 再强制性执行九年制义务教育。而且, 在教学内容中, 要加大结合当地特色经济, 尤其是针对农村经济特点的具体谋生技能和职业教育的分量。

\section{2技术培训是即效的人力资本投资}

如果说教育作为一种长期的人力资本投资, 需要较长的时间周期和资金投入，而对业已 成年的贫困人群而言, 科学技术培训可以在较短时间内提高人力资本素质。农户之所以贫困 是因为缺少知识和高质量的投入。农业部门中自然资源禀赋、自然灾害、农民的生育行为、 文化特征和制度安排等都不是决定农业状况的基本因素, 其根本原因在于资本收益低下。而 现代农业生产要素是打破农业长期形成的经济平衡的最强有力手段。而最有效的提高农业效 率的生产要素就是技术进步。学习和改变意味着外来的文化移入、文化冲击以及与之相随的 文化失调与重构。外来生产技术与生活方式的文化移入, 若能以当地的环境、生态和传统文 化为依托, 进而找到结合的聚合点, 实现技术引进与本土的结合, 就能增强当地人的自身能 力, 并进而转化为反贫困的内在驱动力, 实现其自由发展的权利。

农户的生产理性一一乡土知识的运用, 是他们在长期的生产实践过程中得到并且世代传 承的适应自身农事特点的技术, 代表了农户的技术需求和愿望。他们往往希望能够在原有的 乡土知识基础上实现技术的拓展和创新, 而不是全盘抛弃。实践已经证实, 一项技术经济效 果好而又适应当地条件的新技术, 在贫困农民中推广且普遍被农户自愿接受, 一般需要 5 年甚 
至更长时间。而在技术推广过程中, 除了强调与本土知识的结合外, 还需要考虑农户对新技 术接受的心理承受力, 虽然其经济行为有理性, 但长期封闭的环境, 使其受传统观念和经验 影响较深, 勉强糊口的生活状态对风险承担力低, 从而对接受新技术有心理阻力。而且分散 的环境又阻碍了强制性模式的技术扩散速度。技术的吸收同样需要较长时间。

外来的技术人员具有的是现代化的科学知识体系, 这些知识是规范、封闭的实验室产物, 是教科书式的标准化模式, 无需过多考察各种政治、经济、文化条件等变量。而对于当地人 而言, 他们既有的知识构成使其无法具有与技术人员相当的逻辑思维能力, 也不习惯于书本 上的科学规范的操作过程。农户在决策中, 要考虑技术可操作性、风险性、获利水平等现实 因素, 因此, 期待农户能够按照技术人员要求进行规范化操作是不现实的。如果要让知识成 为穷人头脑的一部分，技术的推广只能走一条能分清经济界限和贫困局限性的路线，即 “ 折 中” 技术。这种折中技术与本土的落后技术相比，生产效率高于现代工业的资本密集型技术， 它不仅在财力方面, 而且在穷人的教育、才能、组织能力等方面都是 “力所能及” 的。是现 实与理论的有效结合, 是切合当地实际需要的新技术。

\section{3劳动力转移是促进人力资本投资的有效配置手段}

经济的开放性在于生产要素的流动性。而贫困农村恰好缺乏流动性: 土地要素是非流动 的, 本身就匮乏的资金也不具有流动潜力, 农产品由于地理位置和交通不便也未充分进入市 场。只有劳动力这一要素相对而言是低成本、高流动性的要素。目前, 农村每年诸多青壮年 劳动力自发地外出打工, 大多从事饮食服务和建筑业。由于务工收入较低, 无法靠打工来维 持家里的运转, 成家后的村民都没有外出打工的现象。对于村民来讲, 他们在有强烈的外出 打工动机的同时，又不了解外地经济发展情况和劳动力需求信息。

劳动力外出打工对农村扶贫的积极作用是多方面的。首先, 它可以缓解人口对土地的压 力, 还土地以喘息和自我修复能力, 有助于当地仅直于土地过度单一开发的贫困恶性循环。 其次, 务工可以提高家庭收入, 降低农业收入的波动性。这样就可以增加农户抵御风险的能 力, 可以为某些风险大但回报率高的农业技术提供支持, 从而改进劳作方式。再次, 务工收 入可以增加家庭积蓄, 使家庭经营多样化。即使是初期进入一些低端产业就业, 也可以在其 中得到经济和非经济的收益。而这些切实的好处对于贫困农村而言是迫切需要的。

加强农村劳动力流动目前最为切实可行的方法是建立乡村职业介绍机构。机构的工作人 员可以由农业技术员来兼任, 一方面他来往于村、镇较为频繁, 可以经常利用解决农田问题 的时机, 深入到村里调查了解劳动力情况, 统计造册。另一方面可以长期追踪劳动力的流向 和变动情况。而作为乡政府和村委会, 可以利用自身的信息渠道为劳动力寻找就业机会, 广 泛收集用工信息, 联系一批长期用工的单位, 确保就业渠道畅通。在用工过程中, 政府可以 加强与他们的沟通, 解决其实际困难, 让村民敢于外出, 放心外出。外出的初始人员立住脚 跟后, 便会利用各种途径相互联络, 将亲朋好友、左邻右舍介绍到自己就业的地方做伴, 彼 此照应, 相互提携, 进而可以促进外出务工的有序性及自发的组织化程度提高。

\section{4 健康状况是人力资本的储备}

健康投资通过增强人的体质和延长人的寿命来增进人力资本的积累。它可以减少因个体 生病而带来的生产损失, 可以促进利用曾因疾病而未充分利用的自然资源, 也可以增加儿童 的入学机会并使他们更好地学习, 更可以解放用于治疗疾病的资源, 从而使这些资源得以用 于其他的投资和消费。农村初级卫生保健工作属于公共卫生领域。针对农村的现实情况, 医 疗卫生事业应着重于两个问题的解决: 一是要加强目前医务人员的培训, 更新知识, 解决知 识老化问题。二是在资金确实困难的前提下，广泛宣传新型农村合作医疗制度，呼吁民众参 与, 切实依托这一制度解决疾病困扰。此外, 村民觉得真正发生医疗事件时, 审批和报账的 手续很烦琐。如果这一合作医疗制度能够适当地针对农村的现实做出调整, 例如简化医疗程 
序, 提高账户报销比例, 缩减费用报销流程, 将极大地减轻农户的就医负担。从而以社会保 障机制提升人力资本效率。

\section{4. 结语}

精准扶贫工作是一项艰巨而伟大的工作，但是在其中片面追求短期目标和数字化目标的 行为也时有发生, 要避免贫困人口返贫, 就要切实从贫困人口的实际出发, 解决其陷入贫困 困境无法自救的发展需求，从软性指标入手，从长期的发展思路来加大人力资本投资。

\section{References}

[1] Wang Sangui et al. Technology diffusion and poverty alleviation, China agricultural press, pp. 90-100, 1998.

[2] LU min et al. On Agricultural Production System Research, Journal of Agrotechnical Economics, vol.4, 2001.

[3] E. F. Schumacher, the Small Is the Beautiful, translated by Yu hongjun and others, Commercial Press Edition, pp. 125-128, 1984. 